\title{
IMPACT OF KNOWLEDGE ON INNOVATION PROCESS
}

\author{
LEBER, M.; BUCHMEISTER, B. \& IVANISEVIC, A.
}

Abstract: Innovation means renewal and change, but in today's turbulent business world, it has come in particular to mean the development of new corporate services, products, processes and structures. Innovation is a knowledge management process, involving creation, integration, sharing and application of knowledge. In the period of crisis, there must be stronger focus put on research and innovation investments to overcome the challenges of globalization. One of the priorities of nowadays should be to improve innovation performance of enterprises. In the chapter, we present a review, how successful learning organizations adopt a culture based on innovation and management support for innovation, and describe the relationship between innovation, knowledge and strategic planning. The development and application of new knowledge is the basis of innovation, emphasizing the strong links between innovation and knowledge.

Key words: Innovation management, Knowledge management, Innovation process, Learning process
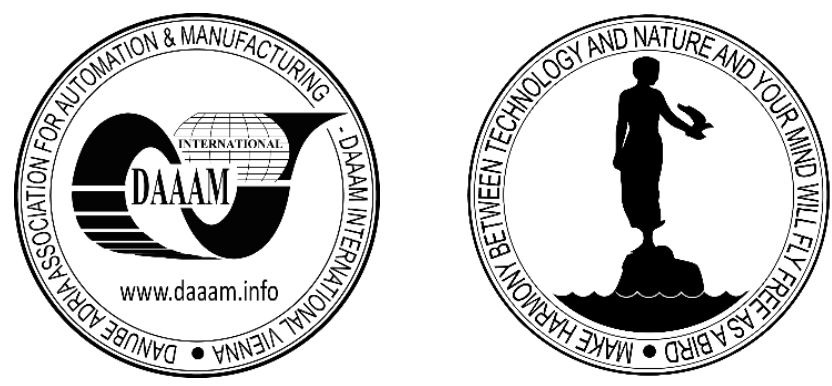

Authors' data: Asst. Prof. Dr. Sc. Leber, M[arjan]*; Full Prof. Dr. Sc. Buchmeister, B [orut]*; Assoc. Prof. Dr. Sc. Ivanisevic, A[ndrea]**, *University of Maribor, Faculty of Mechanical Engineering, Production Engineering Institute, Smetanova 17, 2000 Maribor, Slovenia, EU, **University of Novi Sad, Faculty of Technical Sciences, Trg Dositeja Obradovica 6, 21000 Novi Sad, Serbia, marjan.leber@um.si, borut.buchmeister@um.si, andreai@uns.ac.rs

This Publication has to be referred as: Leber, M[arjan]; Buchmeister, B[orut] \& Ivanisevic, A[ndrea] (2015). Impact of Knowledge on Innovation Process, Chapter 21 in DAAAM International Scientific Book 2015, pp.235-248, B. Katalinic (Ed.), Published by DAAAM International, ISBN 978-3-902734-05-1, ISSN 1726-9687, Vienna, Austria

DOI: 10.2507/daaam.scibook.2015.21 


\section{Introduction}

In the turbulent times when time of prosperity is followed by the crises and globalization of the market, it is inevitable to set up the tools that maintain sustainability and permanent growth of enterprises (Caganova et al., 2010). Global surveys on Innovation and Knowledge management proved that competitiveness is possible only via cooperation, networks, communities and international research and development.

Firms are both systems of interlinked operating processes and knowledge organizations. On the one hand, resources are configured and managed to keep the mainstream flowing". On the other hand, new knowledge is introduced through new stream (Kanter, 1989). New knowledge is central to the innovation. However, knowledge itself does not ensure profits. The value of knowledge lies on its effect on mainstream. Successful innovation requires linking knowledge to operating processes in an effective and efficient way. As Schumpeter noted, innovation is not only the invention of something new, but also more importantly the successful exploitation or commercialization in the market of this invention (Schumpeter, 1934). In this view, novelty and commercialization are two key distinguishing features to recognize innovation. From the knowledge-based view or knowledge management perspective, novelty comes from knowledge creation whereas commercialization is accomplished by knowledge application. The newly created knowledge contributes to the necessary diversity for organizational growth and renewal, while the application of knowledge leads to performance improvement or value creation. Thus, knowledge creation and application are two basic aspects of innovation. Knowledge creation is associated with that part of the innovation process through which new knowledge is introduced. Knowledge application is the process of putting knowledge into practice to realize the latent potential of knowledge. Innovation is a knowledge management process that extracts new value from a firm's knowledge assets.

Innovation means renewal and change, but in today's business world it has come in particular to mean the development of new corporate services, products, processes and structures (Bornemann et al., 2003). The development and application of new knowledge is the basis of innovation, emphasizing the strong links between innovation and knowledge.

\section{Innovation management}

Innovation is a complex process, involving a variety of factors at different levels (Kong \& Li, 2007). Innovation process and the factors that affect it should be coordinated and managed in a systematic way.

The definitions for innovation are almost as varied as the number of researchers that have studied the concept (Katz \& Preez, 2008). A possible reason for this is the variety of different disciplines that have focused their attention on innovation and based on their particular perspective and experiences a definition was formed. Despite these differences, certain themes seem to be repeated throughout the literature. Based on these themes innovation in this chapter is described as the: 
- successful generation, development and implementation of new and novel ideas, WHICH

- introduce new products, processes and/or strategies to a company OR

- enhance current products, processes and/or strategies LEADING TO

- commercial success and possible market leadership AND

- creating value for stakeholders, driving economic growth and improving standards of living.

Martensen and Dahlgaard (1999) explain that excellence in innovation requires that companies are able to react quickly to changes in their business environment as well as identifying and taking advantage of new possibilities through creative solution development. A range of company characteristics has been identified, which have been shown to improve a company's ability to react efficiently, effectively and innovatively to change (Katz \& Preez, 2008). These characteristics include:

- senior management passion and commitment (Simon et al., 2003),

- managers with staff support and integrity (Johannessen et al., 1999),

- integrated internal processes (Neely et al., 2001),

- understanding the larger market and technological environment (Neely et al., 2001),

- a culture and structure which promotes innovation (Hamel, 2000),

- an open market for capital investment and rewards (Hamel, 2000),

- managing the risks (Hamel, 2000).

Palcic et al. have analysed the differences in the use of organisational concepts depending on the company size and technological intensity. They also present the trends in use of organisational innovation concepts and future plans of companies. They show that the use of specific technical and organisational innovation concepts is quite diverse (Palcic et al., 2014).

There are two perspectives of innovation, namely: thing-oriented and processoriented (Abou-Zeid \& Cheng, 2004). According to the first perspective, innovation is conceived as a discrete product or outcome, "a new idea, product or device" (Damanpour \& Evan, 1984; Kimberly \& Evanisko, 1981) whereas, according to the second perspective, it is conceived as "the process of introducing something new" (Rogers, 1983; Van de Ven \& Rogers, 1988). Su et al. have presented customer collaborative product innovation (CCPI) as a novel pattern of new product development to integrate customers and their knowledge as the main innovative agents and resources. Because conflict is an intrinsic and inevitable phenomenon in this process, they have simulated the process of CCPI conflict contagion and verified the influence of different factors on the conflict-spreading trend (Su et al., 2015).

Innovation outcomes can be categorized in sets of contrasting types based on a certain criterion (Abou-Zeid \& Cheng, 2004). The most frequent criteria are: the target of innovation outcomes (product versus process), the area of impact (technical versus administrative) and the degree of change (radical versus incremental) (Gopalakrishnan \& Damanpour, 1997). More recently, innovation outcomes have been categorized in term of the nature of associated knowledge (Gopalakrishnan \& Bierly, 2001). 


\section{Knowledge management}

Knowledge is incorporated in many facets of the company and "knowledge management can be framed as the problem of creating an efficient and effective knowledge marketplace in the organization" (Grover \& Davenport, 2001).

Probst et al. (2000) suggest that knowledge management is the management of a company's corporate knowledge and information assets as well as its business processes to encourage a better and more consistent decision-making. Knowledge management is recognized as the fundamental activity for obtaining, growing and sustaining innovation in organizations in a rapidly change environment (Malhotra, 2000). Davenport and Grover (2001) and Liebowitz (2000) support that the successful use of company's corporate knowledge across its business processes increase a longterm success and growth. Nonaka and Takeuchi (1995) conceptualize knowledge management as the management of those processes that manage the generation, dissemination and utilization of knowledge. A knowledge management process can be structured into three continually interacting phases: knowledge acquisition (KA), knowledge distribution (KD) and knowledge utilization (KU) (Rounti, 2009). Although there are many attempts to define knowledge, it is an ambiguous and rich concept, which points many directions simultaneously.

Individual knowledge is the knowledge possessed by individuals. Knowledge is intrinsically linked to people, since they know and have the skills to act. On the other hand, organizational knowledge refers to the knowledge commonly shared within the organization, that is, a collective understanding. Organizational knowledge is shaped by the organizational routines, symbols, behavioural norms and values, etc., that is, the organizational culture, which has been developed over time and, thus, is distinctive of the firm. Thus, the organizational culture is a valuable, rare and imperfectly imitable. The strategic importance of organizational knowledge has aroused in the new economy, since due to the globalization of the markets individuals easily move from firms taking their experiences with them. Therefore, it is based on knowledge management life cycle: knowledge creation, knowledge storage and retrieval, knowledge transfer and knowledge application.

Knowledge management cycle might happen at different levels within the organization, from the individual level to the external level (Rounti, 2009). The adoption of this perspective is also very interesting since it might allow us to identify what levels in the organizations are stronger or weaker, whether some of them are more significant than others, etc.

\section{The connection between knowledge and innovation}

Firms are both systems of interlinked operating processes and knowledge organizations. On the one hand, resources are configured and managed to keep the mainstream flowing". On the other hand, new knowledge is introduced through new stream (Kanter, 1989). New knowledge is central to the innovation. However, knowledge itself does not ensure profits. The value of knowledge lies on its effect on mainstream. Successful innovation requires linking knowledge to operating processes 
in an effective and efficient way. As Schumpeter noted, innovation is not only the invention of something new, but also more importantly the successful exploitation or commercialization in the market of this invention (Schumpeter, 1934). In this view, novelty and commercialization are two key distinguishing features to recognize innovation. From the knowledge-based view or knowledge management perspective, novelty comes from knowledge creation whereas commercialization is accomplished by knowledge application. The newly created knowledge contributes to the necessary diversity for organizational growth and renewal, while the application of knowledge leads to performance improvement or value creation. Thus, knowledge creation and application are two basic aspects of innovation. Knowledge creation is associated with that part of the innovation process through which new knowledge is introduced. Knowledge application is the process of putting knowledge into practice to realize the latent potential of knowledge. Innovation is a knowledge management process that extracts new value from a firm's knowledge assets.

Innovation means renewal and change, but in today's business world it has come in particular to mean the development of new corporate services, products, processes and structures (Bornemann et al., 2003). The development and application of new knowledge is the basis of innovation, emphasizing the strong links between innovation and knowledge. With the implementation of these mentioned ideas companies could achieve important competitive advantages and improved strategic orientation in the global market.

The core competence of a company can be divided into several levels (Fig. 1). Activities at a knowledge domain level focus on the continued development of the core knowledge domains. In general, this involves a variety of different knowledge holders and can include external knowledge domains and expertise from cooperation partners.

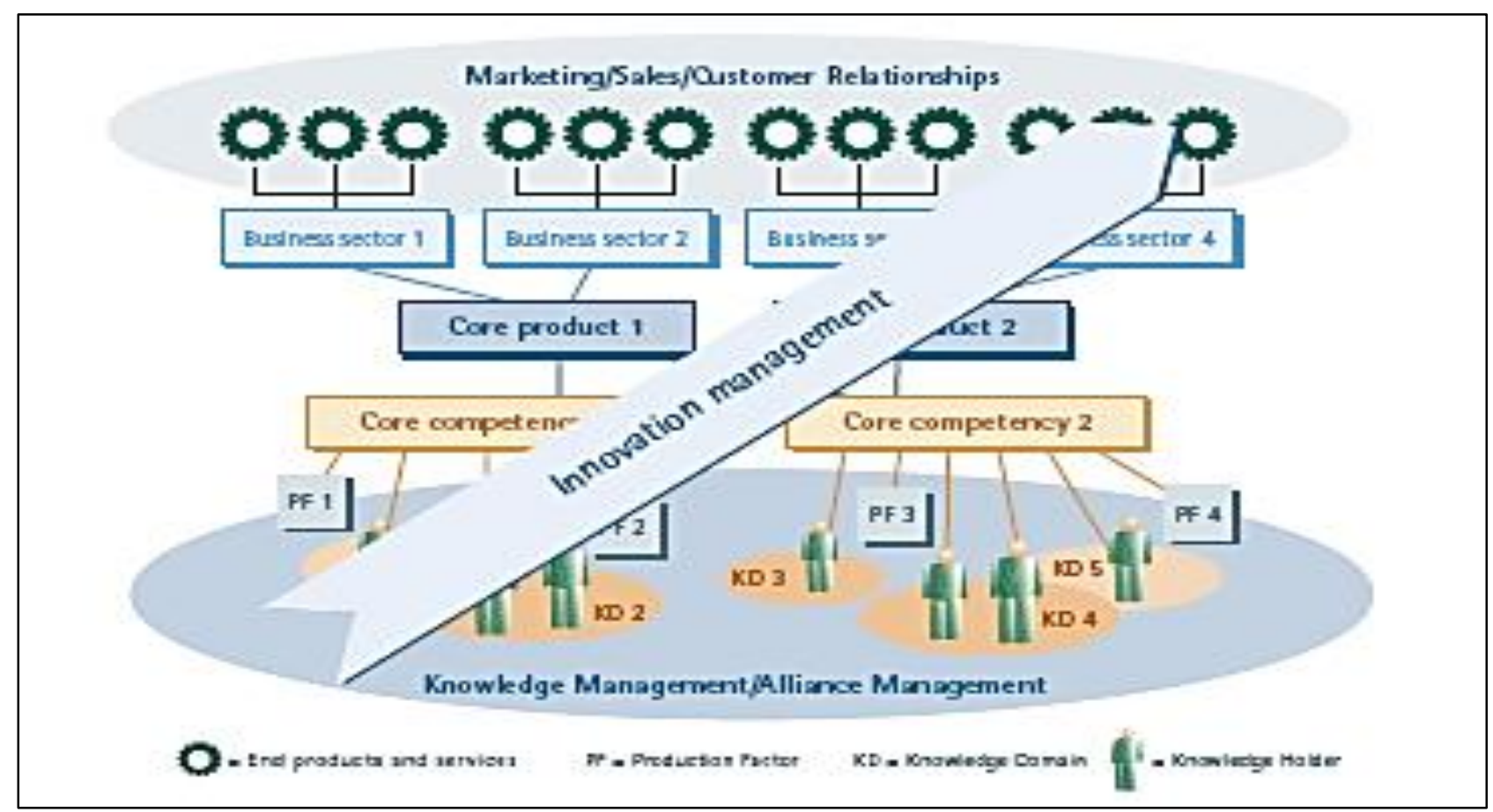

Fig. 1. Innovation management turns knowledge into profit (Bornemann et al., 2003) 
Combining the factors of production (including in this case knowledge) leads to the development of core competences, core products and, ultimately, end products. In other words, returns are generated from any knowledge created.

This can be a long process and it may well take several years from knowledge development until a response is received from the target market for the products and services. Organizing this process is one of the tasks of professional innovation management. Effective innovation management steers the process from knowledge development to realization and commercial exploitation of the results.

Innovations are not created directly; they are only created once all the factors involved have combined appropriately. Organizations are purposeful systems containing purposeful parts - people, and groups of people, physical assets, and technology. These actors can act together, producing systemic behaviour that the parts cannot produce on their own but for which they are mutually causally responsible. That means that all factors should be aligned and orchestrated around the theme of innovation. Innovations often are oriented to problem. They are the processes where knowledgeable and creative people and organizations frame problems and select, integrate, and augment information to create understandings and answers (Teece, 2001).

Innovation adds value through knowledge (Kosturiak, 2010). The knowledge management is a set of processes, policies, and tools that link knowledge of employees to new sources of value (products, services, processes) in order to create innovative solutions. Innovation is a systematic and radical change, which brings a new value for the customers, who is able to pay for it (Zeleny, 2005):

1 . The company performance efficiency is measured by the fast ability of reaction today:

- The faster is responded to the abnormality in the process the less it costs and the faster is responded to the customer's demand the faster the money is received - the operational flexibility.

- The sooner and more innovatively is responded to the key changes on the markets the larger competitive advantage is created - the strategic flexibility.

- The ability of immediate response strongly depends on correct information and knowledge.

2. Information is not knowledge. The knowledge is a correct utilization of information in action.

3. The difference between good and bad firms consist in the fact what information and knowledge they have and how they are able to utilize it. The difference is in people and utilizing their knowledge.

4. Each company has two basic functions:

- Production and development products and services - this is the prerequisite for earning money, making profit and growing company.

- Self-reproduction - creating knowledge and development of people - this is the prerequisite for long-term mastering of the function 1.

The companies should be able to solve the following important questions regarding the knowledge management: 
1. How to reach and keep the best talents and individuals?

2. How to share, communicate and develop the best corporate practices in the organization?

3. How to transfer knowledge between employees on the projects and actions in the company?

4. How to increase and measure knowledge?

5. How to change knowledge into innovation as fast as possible?

It is not enough only to speak about innovations; the innovation process has to be created as the key function in the company.

As Van de Ven and Engleman (2004) noted, four basic issues emerge in studies of $\mathrm{KM}$ and innovation. The first is the human issue concerning people's focus on making organizations more innovative by exploring new knowledge rather than exploiting existing knowledge. The second is the process issue of how to develop a process that manages and implements ideas. The third refers to a structural problem of building an infrastructure across organizational boundaries for absorbing and learning knowledge as well as facilitating, supporting, and promoting innovation activities. The final one addresses the leadership issue concerning the creation and management of a context that is appropriate for innovation.

Scholars have examined these four issues by investigating internal and external factors that influence $\mathrm{KM}$ and innovation strategies. Internal factors include organizational structures, control and coordination mechanisms, communication channels, and organizational cultures. External factors refer to a set of contextual contingencies that have an effect on KM and innovation activities.

The knowledge-based view (KBV) has expended much effort on types of knowledge, knowledge creation and the relationship between knowledge and individual and organizational learning and other issues but the specification of the connection to innovation is less well established (Johnston \& Paladino, 2007). It is implicit or taken for granted rather than demonstrated. Penrose (1959) made three important contributions to understanding the knowledge/innovation link. First, she argued that any resource (e.g. knowledge) should be considered as a bundle of potential services. Second, it was the (productive) services yielded by the resources that were the central analytical factor, since they were the inputs into the growth of the firm rather than the resources themselves. Third, she proposed that the productive services are the outcome of how the resources of the firm are managed. This is a key assertion because for examination of the relationship between the management of the primary intangible resource, knowledge, and the innovation process.

For open learning to be effective between organizational members firms must have mechanisms to assist and enable the management of knowledge and innovations (Johnston \& Paladino, 2007). Communication channel usage must therefore be frequent and clear and encourage continuous information exchange and learning (Helleloid \& Simonin, 1994). This information exchange assists a firm in all of Nonaka's (Nonaka, 1994; Nonaka \& Takeuchi, 1995) knowledge creating processes and also contributes to the development of organizational memory (Sabherwal \& Becerra-Fernandez, 2003). 
The thing-oriented and process-oriented approaches adopted in the studies noted above are helpful in understanding the relationship between knowledge management concepts and innovation concepts.

Gopalakrishnan and Bierly (2001) classify the knowledge associated with innovation in three dimensions: tacit-explicit, systemic-automatic, and complexsimple. The tacit-explicit dimension is well established in the literature and is closely related to other dimensions of codifiability, teachability, observability and articulateness (Nonaka, 1994; Polanyi, 1966). Whereas tacitness is associated with the ease of knowledge transfer, the systemic-autonomous dimension focuses on integrateability, i.e., the extent to which knowledge components can be linked with other knowledge components, and the complex-simple dimension focuses on the extent of sophistication of knowledge incorporated in the innovation (Abou-Zeid \& Cheng, 2004).

Continuous learning and an innovative culture have a positive effect on the growth of knowledge stock (Liao et al., 2007). These authors state that organizations, that encourage learning and commitment to innovation, obtain more efficient programs, focused on the internal development of technological competences.

The promotion of innovation distinctive competences and the introduction of KM can strengthen the sustainability of the competitive advantages generated (Palacios et $a l ., 2008)$. The way KM is configured in an organization is unique, since the principles and practices used depend on the social and technological context of the firm. The possibility a firm has of appropriating the profits generated by its resources depends on the existence of perfectly defined property rights. The profits generated are the result of a complex network of relationships and are not attributed to determined production factors. It is considered that KM enables firm profits to be appropriated since it promotes group work, and encourages the sharing of knowledge and the breaking down of interdepartmental barriers (Smith et al., 2005). In fact, the more an individuals' knowledge is inserted into organizational routines, the greater the possibility of the firm appropriating the results.

The innovation ability is the key towards overcoming the economic crisis and it puts the basis for the evident and sustainable growth (Caganova et al., 2010). The authors of the article are identified with the fact that: "Knowledge lies at the very heart of innovation. A company's ability to create, store and transfer knowledge the innovation process itself may well determine success in bringing new products about technologies customer needs and/or services to the market" (Inganas et al., 2006).

Capability of the firm to innovate, according to the Oslo Manual, also depends on the characteristics of the firm: the structure of its labor force and facilities (skills, departments), its financial structure, strategy on markets, competitors, alliances with other firms or with universities, and above all its internal organization. Many of these aspects are complementary. A particular skill structure will go hand in hand with a particular type of strategy, financial structure and so on.

A company's capacity to innovate is dependent on its capability to integrate internal processes (i.e. how well a company brings together information and people from different areas) and its capability to understand the larger market and technological environment (Neely et al., 2001). 
A company has to manage knowledge regarding a variety of different facets of the business in order to innovate successfully (Katz \& Preez, 2008). These facets include:

- external environment (competitors, technology, legislation, markets),

- internal environment (performance data, strategy, processes, products, organisational structures, culture, politics),

- inter and intra project.

If a company is able to manage the knowledge of these different business facets then knowledge management will support innovation in the following ways:

- Providing a common view of the current company environment thereby supplying the first step in the transition process (AS-IS situation), identifying internal opportunities for innovation and creating buy-in for the innovation.

- Providing a view of the industry environment thereby focusing the innovation on improving competitiveness.

- Providing a view of the client requirements thereby ensuring the innovation is inline with client's needs and expectations.

- Providing a view of the latest technological developments thereby ensuring the radical innovation project uses the latest technologies in an optimal way.

- Speeding up innovation by assisting with project integration and knowledge sharing between projects.

The innovation process is about the generation of new knowledge and companies that wish to gain a competitive advantage through innovation require the correct systems, processes and culture to manage knowledge (Carneiro, 2000).

Many organizations have expressed their dissatisfaction with the results obtained after introducing KM programs (Palacios et al., 2008). Key questions are often asked, such as: How should the KM concept be managed? How should knowledge be captured, stored and transferred? How could innovation distinctive competences be created?

Every firm develops $\mathrm{KM}$ principles in different contexts. However, it is considered appropriate to determine a set of common principles that should be incorporated into a KM system.

The impetus for innovation projects can come from two different sources (Fig. 2): unplanned innovation occurs directly in day-to-day business activities and is often the incremental result of a new customer project; planned innovation on the other hand actively utilizes the knowledge resources available both in and to the company in developing new value-creating projects.

Periodic innovation checks serve to analyse the status of a company's core competence tree, as well as relevant trends and developments in its environment. The results can then be used to develop or modify an innovation strategy and define the scope and aims of innovation projects.

In practice, it has proved effective to split an innovation process/project into the following phases: developing ideas, testing ideas, realizing ideas, and exploiting ideas. Most of innovations today are unplanned, but contemporary concepts lead to systematic development of planned and focused innovations (open innovation). 
Leber, M.; Buchmeister, B. \& Ivanisevic, A.: Impact of Knowledge on Innovation ...

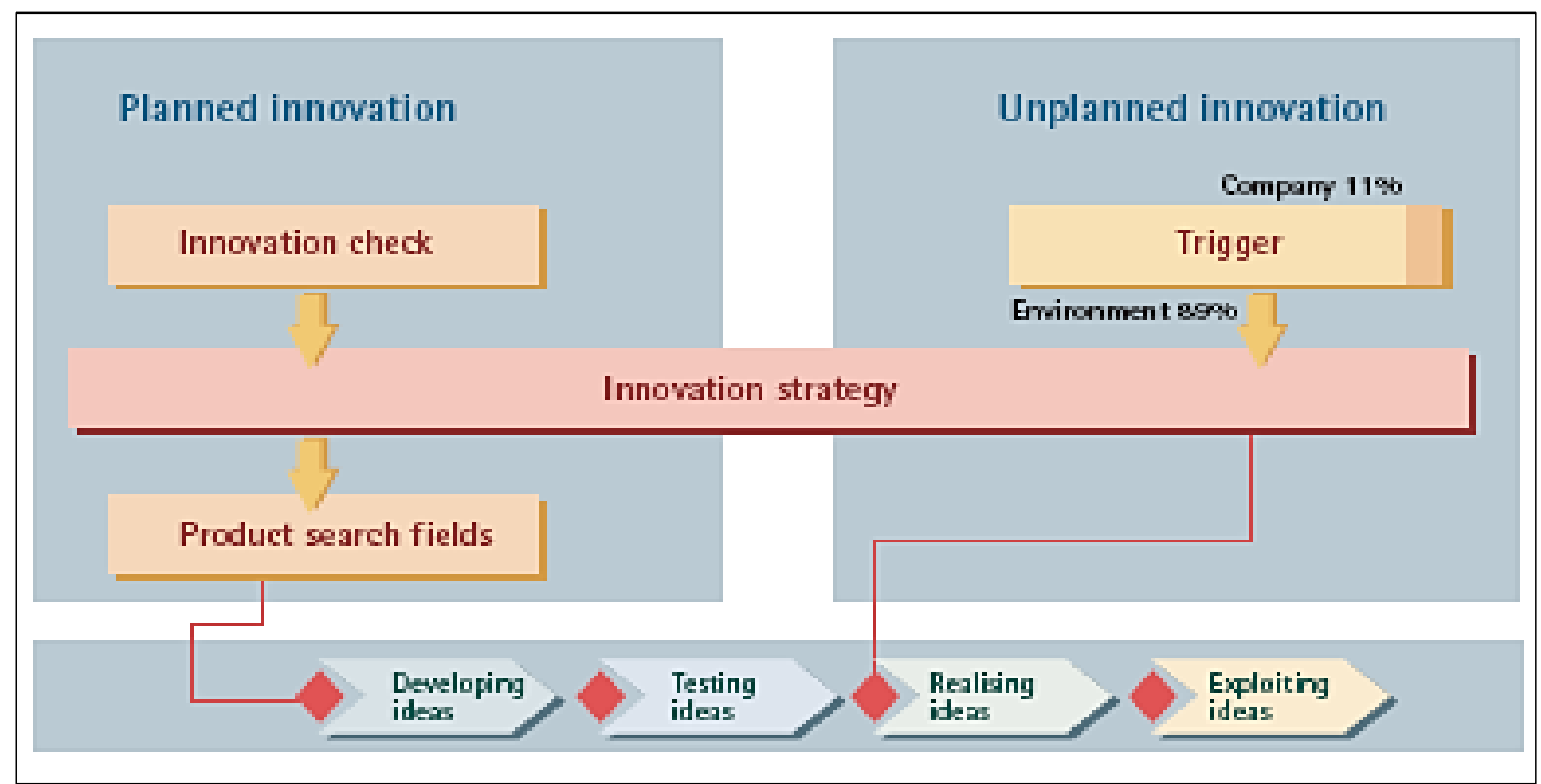

Fig. 2. Different innovation activities in a company (Bornemann et al., 2003)

The development phase focuses on applying creativity methods (e.g. brainstorming) to identify or unlock creative potential. The most promising ideas (success rate approximately $12 \%$ ) are then filtered out in the testing phase. The ideas should now be researched in detail to ensure they are not already covered by existing intellectual property rights. New knowledge can be protected by strategic patenting.

Promising ideas that pass the testing phase are then developed in the subsequent realization phase. Project management, knowledge logistics, business planning and innovation marketing activities are all key elements in this phase. In the exploitation phase, the new products, services or licenses must be turned quickly into profits.

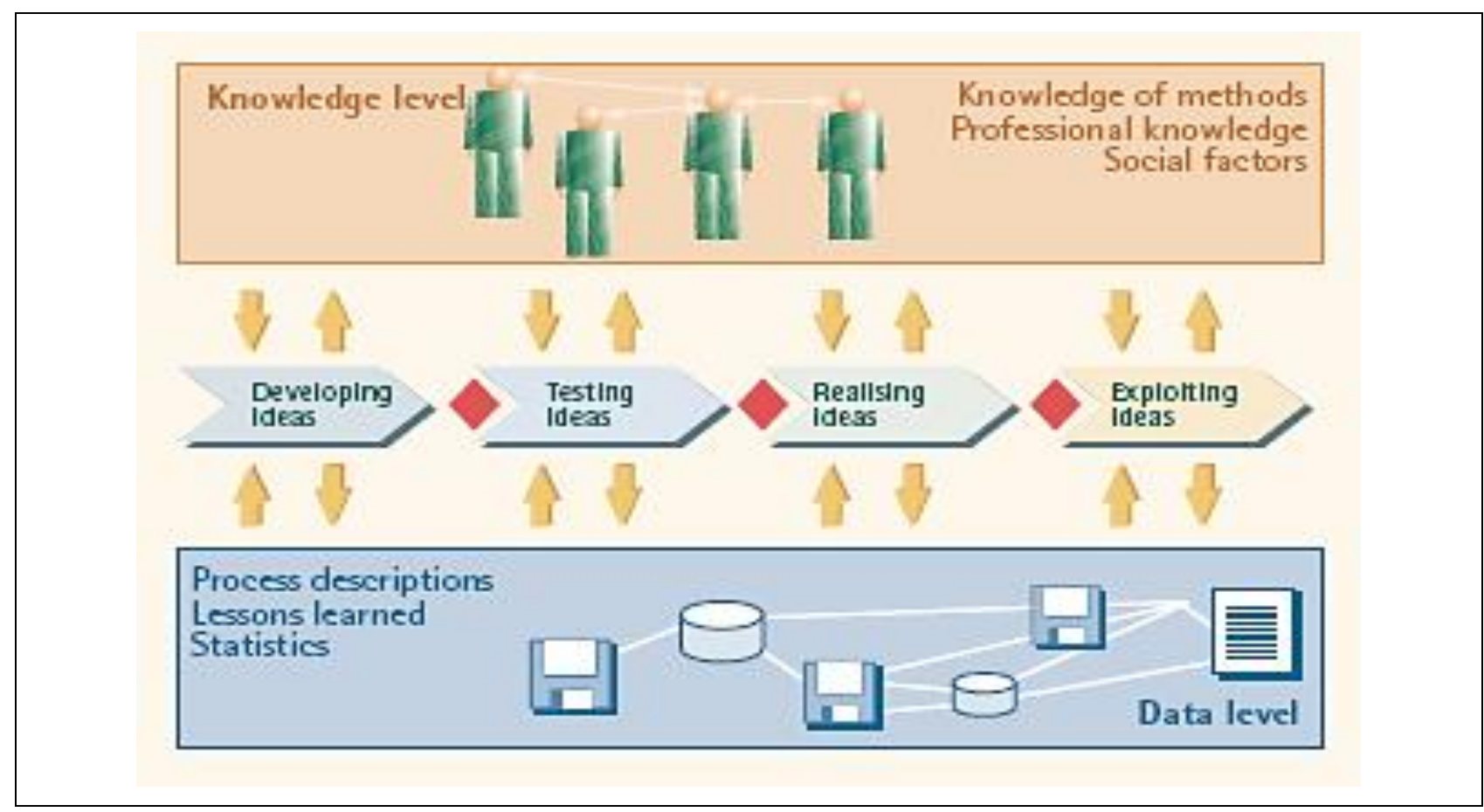

Fig. 3. Knowledge processes in innovation projects (Bornemann et al., 2003) 
Knowledge management forms the basis for effective and efficient innovation management. This involves interaction between three different levels (Fig. 3). The project level must be clearly structured into the four innovation phases described above. The experts (with their professional and methodological knowledge and social skills) are located on the knowledge level and communicate directly with the project level. All the data and documents relevant to innovation are collected at the data level. These can be made available throughout the innovation process using modern information and communication tools. Smooth integration between the knowledge and data levels is a key factor in successful innovation projects.

According to Gerard (2002) innovation will take a great significance and require a new kind of professional employee. The new skill sets include system and knowledge integration as well as the ability to manage complexity and uncertainty and to work in a multicultural environment - all of these skills are the essence of innovation (Caganova et al., 2010).

\section{Conclusion}

Both of socio-cultural view and practice perspective of knowledge assume that learning is a complex social process and new knowledge often is socially constructed and embedded within routine working practices (Brown \& Duguid, 2001). More often collective learning and knowledge sharing is achieved by "bottom-up" interaction and self-organizing, which require collaborative relationships among people or organizations (Kong \& Li, 2007). Hence, firms should promote the development of human capital by developing right culture and incentive mechanism. If not, excellent human capital does not necessarily produce radical innovations successfully (Subramaniam \& Youndt, 2005).

Increasing number or research shows that change is the main characteristic of business environment. Companies need to learn and act faster than their competitors in order to acquire sustained competitive advantage in a fast-changing, increasingly competitive business environment. Organization's ability to continuously innovate its products/services and business model is essential to its future success since technology has an extensive impact on the society and economy nowadays. Ongoing innovation is a key requirement in conditions of hyper competition. Innovation is the source of a company's competitiveness, soul of a company's progress and an inexhaustible power for development.

Collective learning and knowledge sharing are necessary prerequisites for innovations in organizations and the organizational learning, organizational knowledge and innovations are essential conditions for improving performance. The capacity to learn and innovate is crucial for increasing the organization's value.

Innovation is conceived as an individual and collective learning process with the aim of finding new ways of solving problems. Therefore, innovation seems to depend on the organization's capability to learn, through which new knowledge is developed, distributed and used. There is a positive link among the organizational requirements for learning and innovation, the main learning output. Our research sets the major point to manufacturing SMEs as a key limitation of this work. 
Leber, M.; Buchmeister, B. \& Ivanisevic, A.: Impact of Knowledge on Innovation ...

Organizational knowledge and innovation are the most critical intangible assets that a company needs to acquire and exploit in order to achieve superior organizational performance.

Innovation is a knowledge management process that involves creation, integration, sharing and application of knowledge. Human capital contains the crucial knowledge in organizations. Company's innovative performance is at least partially a function of its human capital value. On the other hand, human capital is crucial to an organization's ability to adapt to a fast changing environment as a synonym of the business environment of the $21^{\text {st }}$ century.

\section{References}

Abou-Zeid, E. S.; \& Cheng, Q. (2004). The Effectiveness of Innovation: A Knowledge Management Approach. International Journal of Innovation Management, Vol. 8, No. 3, 261-274, ISSN1363-9196

Bornemann, M.; Graggober, M.; Hartlieb, E.; Humpl, B.; Koronakis, P.; Primus, A.; Ritsch, K.; Rollett, H.; Sammer, M.; Tuppinger, J.; Willfort, R. \& Wols, K. (2003). An Illustrated Guide to Knowledge Management, Wissensmanagement Forum Graz Austria, Available from: http://www.wm-forum.org Accessed: 2015-09-15

Brown, J. S. \& Duguid, P. (2001). Knowledge and organization: a social-practice perspective. Organization Science, Vol. 12, No. 2, 198-213

Caganova, D.; Sujanova, J. \& Lenhardtova, Z. (2010). The Multicultural Environment Influence on Innovation and Knowledge Management in the Slovak Republic. Annals of DAAAM for 2010 \& Proceedings of the $21^{\text {st }}$ International DAAAM Symposium, Katalinic, B., pp113-114, ISBN 978-3-901509-73-5, Zadar, Croatia, October 2010, Published by DAAAM International, Vienna

Carneiro, A. (2000). How does knowledge management influence innovation and competitiveness?. Journal of Knowledge Management, Vol. 4, No. 2, 87-98, ISSN $1367-3270$

Damanpour, F. \& Evan, W. (1984). Organizational innovation and performance: The problem of "organizational lag". Administrative Science Quarterly, Vol. 29, No. 3, 392-409, ISSN 00018392

Gerard, H. G. (2002). Innovation by design: what it takes to keep your company on the cutting edge, AMACOM Div American Mgmt Assn, ISBN 0814406963, New York Gopalakrishnan, S. \& Bierly, P. (2001). Analyzing innovation and adoption using a knowledge-based approach. Journal of Engineering and Technology Management, Vol. 18, No.2, 107-130, ISSN 0923-4748

Gopalakrishnan, S. \& Damanpour, F. (1997). A review of innovation research in economics, sociology and technology management. Omega: The International Journal of Management Science, Vol. 25, No. 1, 15-28 ISSN 0305-0483

Grover, V. \& Davenport, T. H. (2001). General Perspectives on Knowledge Management: Fostering a Research Agenda. Journal of Management Information Systems, Vol. 18, No. 1, 5-21, ISSN 0742-1222

Hamel, G. (2000). Leading the Revolution, Harvard Business School Press, ISBN 1591391466, Boston 
Inganas, M., Hacklin, F., Pluss, A. \& Marxt, C. (2006). Knowledge management with focus on the innovation process in collaborative networking companies. International Journal of Networking and Virtual Organisations, Vol. 3, No. 3, 283-298, ISSN 14709503

Johannessen, J. A., Olaisen, J. \& Olsen, B. (1999). Managing and organizing innovation in the knowledge economy. European Journal of Innovation Management, Vol. 2, No 3, 116-128, ISSN 1460-1060

Johnston, S. \& Paladino, A. (2007). Knowledge Management and Involvement in Innovations in MNC Subsidiaries. Management International Review, Vol. 47, No. 2 , 281-302, ISSN 09388249

Kanter, R. M. (1989). Swimming in newstreams: mastering innovation dilemmas. California Management Review, Vol. 31, No. 4, 45-69

Katz, B. \& Preez, N. D. (2008). The Role of Knowledge Management in Supporting a Radical Innovation Project, In: Methods and Tools for Effective Knowledge Life-CycleManagement, Editors: Bernard A. \& Tischkiewitsch S., 331-345, Springer, ISBN 9783-540-78430-2, Berlin Heidelberg

Kimberly, J. \& Evanisko, M. (1981). Organizational innovation: The influence of individual, organizational, and contextual factors on hospital adoption of technological and administrative innovations. The Academy of Management Journal, Vol. 24, No. 4, 689-713, ISSN 0001-4273

Kong, X. Y. \& Li, X. Y. (2007). A Systems Thinking Model for Innovation Management: The Knowledge Management Perspective. Procedings of 2007 International Conference on Management Science \& Engineering $\left(14^{\text {th }}\right)$, Yin Ji-rong, pp 1499-1504, ISBN 978-5603-2278-0, Harbin, Aug. 2007, Harbin Institute of Technology Press, Harbin, China

Kosturiak, J. (2010). Innovations and knowledge management. Human Systems Management, Vol. 29, 51-63

Liao, S., Fei, W. \& Chen, C. (2007). Knowledge sharing, absorptive capacity, and innovation capability: An empirical study of Taiwan's knowledge-intensive industries. Journal of Information Science, Vol. 33, No. 3, 340-359, ISSN 0165-5515

Liebowitz, J. (2000). Building organizational intelligence - a knowledge management example, CRC Press LLC, ISBN 0-8493-2036-4, Boca Raton Florida

Malhotra, Y. (2000). Knowledge Management for E-business Performance. Information Strategy: The Executives Journal, Vol. 16, No. 4, 5-16, ISSN 0743-8613 Martensen, A. \& Dahlgaard, J. J. (1999). Strategy and planning for innovation management - supported by creative and learning organisations. International Journal of Quality \& Reliability Management, Vo. 16, No. 9, 878-891, ISSN 0265-671X

Neely, A., Filippini, R., Forza, C., Vinelli, A. \& Hii, J. (2001). A framework for analysing business performance, firm innovation and related contextual factors: perceptions of managers and policy makers in two European regions. Integrated Manufacturing Systems, Vol. 12, No. 2, 114-124, ISSN 0957-6061

Nonaka, I. (1994). A Dynamic Theory of Organizational Knowledge Creation. Organization Science, Vol. 5, No. 1, 14-37, ISSN 1047-7039 
Leber, M.; Buchmeister, B. \& Ivanisevic, A.: Impact of Knowledge on Innovation ...

Nonaka, I. \& Takeuchi, H. (1995). The Knowledge-creating Company: How Japanese Companies Create the Dynamics of Innovation, Oxford University Press, ISBN 0195092694, New York

Palacios, D., Gil, I. \& Garrigos, F. (2008). The impact of knowledge management on innovation and entrepreneurship in the biotechnology and telecommunications industries. Small Business Economics, Vol. 32, No. 3, 291-301, ISSN 0921-898X

Palcic, I.; Koren, R. \& Buchmeister, B. (2014). Technical and Organisational Innovation in Slovenian Manufacturing Companies, Chapter 02 in DAAAM International Scientific Book 2014, pp. 019-032, Katalinic, B. (Ed.), DAAAM International, ISBN 978-3-901509-98-8, ISSN 1726-9687, Vienna, Austria Penrose, E. T. (1995). The Theory of the Growth of the Firm, Oxford University Press, ISBN 0-19-828977-4, New York

Probst, G., Raub, S. and Romhardt, K. (2000). Managing knowledge: building blocks for success, John Wiley, ISBN 978-0-471-99768-9, Chichester

Rogers, E. (1983). Diffusion of Innovation, The Free Press, ISBN 0-02-874074-2, New York

Rounti, I. S. (2009). Innovation Culture for Knowledge Management in new e-Ra. In: Web 2.0 The Business Model, Miltiadis D. L., Ernesto D., Patricia Ordonez de P., 293307, Springer Science+Business Media, ISBN 978-0-387-85894-4, New York

Schumpeter, J. (1934). The Theory of economic development, MA: Harvard University Press, ISBN 0-87855-698-2, Cambridge

Simon, E. S., McKeough, D. T., Ayers, A. D., Rinehart, E. \& Alexia, B. (2003). How to Best Organise for Radical Innovation?. Industrial Research Institute, Vol. 46, No. 5, 17-20, ISSN 0895-6308

Su, J. F.; Yang, Y.; Yang, T.; Zhang, X. F. \& Liu, L. (2015). Simulation of Conflict Contagion in Customer Collaborative Product Innovation, International Journal of Simulation Modelling, Vol. 14, No. 1, pp. 134-144, ISSN 1726-4529

Subramaniam, M. \& Youndt, M. (2005). The influence of intellectual capital on the types of innovation capabilities. Academy of Management Journal, Vol. 48, No. 3, 450-463, ISSN 0001-4273

Teece, D. J. (2001). Strategies for managing knowledge assets: the role of firm structure and industrial context, In: Managing Industrial Knowledge: Creation, Transfer and Utilization, Nonaka, I. \& Teece, D. J. (Eds.), 125-144, Sage Publications Ltd, ISBN 076195498 8, London

Van de Ven, A. \& Engleman, R. (2004). Central problems in managing corporate innovation and entrepreneurship. Advances in Entrepreneurship, Firm Emergence and Growth, Vol. 7, 47-72, ISSN 1074-7540

Van de Ven, A. \& Rogers, E. (1988). Innovations and organizations: Critical perspectives. Communication Research, Vol. 15, 623-651, ISSN 0093-6502

Zeleny, M. (2005). Knowledge of enterprise: knowledge management or knowledge technology? In: Governing and Managing Knowledge in Asia, Menkhoff, T., Evers, H.-D. \& Chay, Y. W., eds, 23-61, World Scientific Publishing, Vol. 3, ISBN 981-256193-5, Singapure 